\title{
Clinical and cognitive characteristics of children with attention-deficit hyperactivity disorder, with and without copy number variants
}

Kate Langley, Joanna Martin, Sharifah Shameem Agha, Charlotte Davies, Evangelia Stergiakouli, Peter Holmans, Nigel Williams, Michael Owen, Michael O'Donovan and Anita Thapar

\section{Background}

Submicroscopic, rare chromosomal copy number variants (CNVs) contribute to neurodevelopmental disorders but it is not known whether they define atypical clinical cases.

\section{Aims}

To identify whether large, rare CNVs in attention-deficit hyperactivity disorder (ADHD) are confined to a distinct clinical subgroup.

\section{Method}

A total of 567 children with ADHD aged 5-17 years were recruited from community clinics. Psychopathology was assessed using the Child and Adolescent Psychiatric Assessment. Large, rare CNVs (>500 kb, <1\% frequency) were defined from single nucleotide polymorphism data.

\section{Results}

Copy number variant carriers (13.6\%) showed no differences from non-carriers in ADHD symptom severity, symptom type, comorbidity, developmental features, family history or pre-/ perinatal markers. The only significant difference was a higher rate of intellectual disability $\left(24 \%\right.$ v. $9 \%, \chi^{2}=15.5$, $P=0.001$ ). Most CNV carriers did not have intellectual disability.

\section{Conclusions}

Large, rare CNVs are not restricted to an atypical form of ADHD but may be more highly enriched in children with cognitive problems.

\section{Declaration of interest}

None.
Submicroscopic, rare chromosomal deletions and duplications known as copy number variants (CNVs) have been found to contribute to increased risks of different neurodevelopmental disorders, notably autism, schizophrenia and intellectual disability, and most recently attention-deficit hyperactivity disorder (ADHD). ${ }^{1-9}$ However, the types of CNVs most consistently associated with ADHD and other neurodevelopmental disorders are individually rare $(<1 \%$ frequency). This raises the question of whether such mutations are associated with clinically and developmentally typical disorder. We have previously found that large, rare $\mathrm{CNV}$ s are significantly more common in children with ADHD than those without ADHD. ${ }^{9}$ In the present paper, based on an extension of our previously reported sample, we address a different question. Specifically, we set out to identify whether $\mathrm{ADHD}$ accompanied by the presence of at least one large, rare $\mathrm{CNV}$ is associated with distinctive clinical, cognitive and developmental features, differential family loading of psychiatric disorder and specific pre-/perinatal markers.

\section{Method}

\section{Sample}

Our sample consisted of 567 children aged 5-17 years $($ mean $=10.6$, s.d. $=2.82)$ with a DSM-IV ${ }^{10}$ or DSM-III-R ${ }^{11}$ diagnosis of ADHD or ICD-10 12 diagnosis of hyperkinetic disorder. Participants were referred to the study by clinicians from child and adolescent psychiatry or paediatric out-patient clinics across the UK. All were of White British origin. Children with schizophrenia, known autism-spectrum disorder, bipolar disorder, Tourette syndrome, epilepsy, brain damage or any other known neurological or genetic disorder were excluded from the study prior to analysis $(n=18)$. All children were also screened for autism-spectrum disorder using the Autism Screening Questionnaire (ASQ). ${ }^{13}$ All those who scored above the cut-off point on the ASQ were reassessed using the same items and reviewed by a clinical child and adolescent psychiatrist. Those who still showed high scores or were judged by a clinician to have possible autism-spectrum disorder were excluded.

This sample is an extension of the 366 children included in a previous genome-wide study of $\mathrm{CNV}$ in ADHD. ${ }^{9}$ As such, all methods are identical to those previously described. Ethical approval for the study was obtained from the North West England and Wales Multicentre Research Ethics Committees. Written informed consent from parents and assent from children (and consent for those aged 16 years and older) were obtained for all individuals.

\section{Measures}

Clinical

Attention-deficit hyperactivity disorder symptoms and diagnoses in the child were confirmed using the Child and Adolescent Psychiatry Assessment (CAPA), ${ }^{14}$ a research diagnostic interview undertaken with the parent. The presence of impairment and onset of symptoms/impairment before the age of 7 years that are needed to confirm diagnoses were also assessed using the CAPA. All interviewers were trained to a high level of reliability (kappa $=1.00$ for agreement on ADHD diagnosis). Information on the pervasiveness of ADHD symptoms and impairment in a school setting was obtained using the Child ADHD Teacher Telephone Interview (CHATTI) ${ }^{15}$ or the Conners Teacher Rating Scale. ${ }^{16}$

The CAPA $^{14}$ was also used to assess current symptoms and diagnoses of comorbid oppositional defiant disorder, conduct disorder, anxiety disorders (generalised anxiety, social anxiety, separation anxiety), depression, mania and tic disorders. Symptoms of these comorbid conditions were also assessed using the child version of the $\mathrm{CAPA}^{17}$ for children aged 12 years and 
over. Comorbid symptoms were endorsed if reported by either parent or child. ${ }^{17}$ DSM-IV diagnoses and total current symptom counts for all of the assessed disorders were generated from the CAPA. Total scores from the ASQ were also computed.

\section{Cognitive measures}

Cognitive ability was assessed using the Wechsler Intelligence Scale for Children, ${ }^{18,19}$ which obtains an estimate of full scale IQ. For those aged under 12 years, reading ability was measured using the Wechsler Objective Reading Dimensions (WORD) assessment package. $^{20}$

\section{Pre- and perinatal factors and early development}

Data on pre- and perinatal factors were obtained using a wellvalidated parent-rated retrospective questionnaire, ${ }^{21}$ supplemented with additional questions that have been included in previous investigations. ${ }^{22-24}$ We focused on factors previously found to be associated with ADHD or other neurodevelopmental problems. Parents reported whether the child had spent any time in a special care baby unit, the child's birth weight and the mother's and father's age at the birth of the child. The presence of smoking during pregnancy (yes/no) was assessed using the question 'Did you smoke at all during your pregnancy?' Parents were also asked to report on the child's early development ${ }^{25}$ using measures found to discriminate those with ADHD from those without. Specifically, parents were asked about a delay in speech (not talking by age 2 years), as well as a delay in walking (not walking by age 18 months). Parents were also asked whether their child had suffered from any serious medical conditions. Medical conditions reported by the parent were coded as congenital in origin by two independent physicians (e.g. cardiac murmur coded as congenital, but not asthma).

\section{Family factors}

Parents reported on the family's total annual income and their educational attainment. Low income was defined as annual income $<£ 20000$ and low level of education if one or both parents had left school without qualifications (GCSEs or O-levels at 16 years).

Family history was assessed by asking parents to report on the presence of any mental health problem (ADHD, depression, anxiety, schizophrenia, mania/bipolar disorder and autism) for all first-degree relatives of the index child. This information was used to define the presence of psychiatric disorder in any firstdegree relative. Mothers and fathers (where available) also provided data on their own current (in the past 6 months) and childhood ADHD symptoms. ${ }^{10,26}$ Symptoms that were present at both time points (childhood onset symptoms that continued until adult life) were summed to give a total number of maternal and paternal ADHD symptoms ${ }^{27}$ and these scores were adjusted for parental age using linear regression analysis.

\section{CNV identification}

The ADHD sample used in this study is an extension of the $n=366$ previously analysed for large, rare CNVs and therefore all quality control and CNV detection protocols were identical to those previously described. ${ }^{9}$ Briefly, single nucleotide polymorphisms were genotyped using the Human660W-Quad BeadChip (Illumina, San Diego, California, USA) and BeadStudio was used to call genotypes, normalise the signal intensity data and determine the $\log \mathrm{R}$ ratio and $\mathrm{B}$ allele frequency at each single nucleotide polymorphism according to the standard Illumina protocols. Copy number variants were defined by PennCNV 25 with loci spanning at least 15 consecutive informative single nucleotide polymorphisms, those having copy number calls $<2$ and $>2$ being classed as deletions and duplications respectively. All samples with a single nucleotide polymorphism call rate $<0.95$, a high standard deviation in their genome-wide $\log \mathrm{R}$ ratio ( $>0.30$ ), carrying more than 30 apparent CNVs over $100 \mathrm{~kb}$ or any duplicate or related samples (identity by descent $>0.3$ ) were excluded prior to analysis $(n=40)$. Finally, the application of a number of $\mathrm{CNV}$ validation and quality control procedures (full details previously published $)^{9}$ allowed the definition of the set of large (classified as those $>500 \mathrm{~kb}$ ), rare ( $<1 \%$ frequency) CNVs that were used in this analysis.

\section{Statistical analyses}

The ADHD sample was divided into those with $(n=77)$ and without $(n=490)$ at least one large, rare $\mathrm{CNV}$, greater than $500 \mathrm{~kb}$ in size. The two groups were compared on each of the clinical, cognitive, pre- and perinatal, developmental and family factors. All analyses are presented for raw scores/data for ease of interpretation. To avoid unnecessary multiple testing, the primary analyses were based on quantitative measures where possible and categorical definitions of the same constructs were subsequently tested only if initial association had been found. Where a variable was not normally distributed, the scores were natural logarithmically transformed $(\ln x)$ and analyses were run on transformed scores. Continuous measures were compared across groups using $t$-tests and categorical variables were examined using Pearson chi-squared tests.

As ADHD (like autism and schizophrenia) is associated with lower IQ and its prevalence is higher in individuals with intellectual disability (full-scale IQ $<70$ ), ${ }^{29}$ we did not exclude children with intellectual disability from this study. Results are, however, separately presented for individuals without intellectual disability ( $n=473$, of whom 54 have large, rare CNVs) as well as for the full sample. IQ test scores were not available for 42 children. All analyses were undertaken using SPSS, version 16 for Windows. To take into account multiple testing, using Bonferroni correction for the number of variables tested, alpha was set at $P=0.002(0.05 / 27)$.

\section{Results}

\section{Sample description}

Of the total sample of 567 children, $492(86.8 \%)$ were boys. At the time of assessment, $71.3 \%(n=404)$ currently met criteria for DSM-IV ADHD combined type, $8.3 \%(n=48)$ for inattentive type, $11.8 \%(n=67)$ for hyperactive-impulsive type and $92.9 \%$ $(n=527)$ for current DSM-III-R ADHD. The rates of comorbid disorder were $43 \%(n=244)$ for current DSM-IV oppositional defiant disorder, $15 \%(n=85)$ for conduct disorder, $5.1 \%$ $(n=29)$ for any anxiety disorder and $0.7 \%(n=4)$ for any depressive disorder. Of the total sample, 52 were defined as having intellectual disability (IQ <70), and 473 had IQ test scores of 70 or above ( 42 had scores missing for the Weschler Intelligence Scale for Children). ${ }^{18,19}$ Overall, 490 (86.4\%) children had no large, rare CNV, 69 (12.2\%) had one CNV and 8 (1.4\%) had two CNVs (see online Table DS1 for a full list of CNVs). The proportion of CNV carriers was similar in this extended sample (13.6\%) to our previously reported rate ( $14 \%$ cases $v .7 \%$ controls). ${ }^{9}$

\section{Clinical and cognitive characteristics of children with and without large, rare CNVs}

Table 1 shows the clinical and cognitive characteristics of children with and without CNVs. As age and gender were not associated 
with CNV presence, these variables were not included as covariates in subsequent analyses. As previously observed, ${ }^{9} \mathrm{CNVs}$ were significantly more common in children with intellectual disability (IQ <70) but were not restricted to this group. The majority of CNV carriers in our sample $(n=54,70.1 \%)$ were still in the group of children without intellectual disability. There were associations with lower IQ and reading ability test scores but these did not reach statistical significance following Bonferroni correction. The IQ distributions in the total sample of children with ADHD and the subgroup of CNV carriers are shown in Figs 1 and 2. There were no other clinical phenotypic differences in children with and without CNVs.

When children with intellectual disability were excluded, CNV carriers were still not distinguishable on any clinical characteristic, although CNV carriers showed lower reading ability but not lower IQ scores. The number of children with CNVs in loci previously implicated in autism and schizophrenia was small $(n=20)$ and thus results need to be interpreted with caution. When this group (without intellectual disability) was clinically compared with nonCNV carriers, the pattern of results was similar. No significant differences (after correction for multiple testing) were detected, although CNV carriers showed lower reading ability and, interestingly, ASQ scores (none had autism) were higher (online Table DS2).

\section{Pre-/perinatal, developmental and family factors}

Table 2 shows that children with CNVs could not be distinguished on any pre-or perinatal factor, by an atypical early developmental history or by familial loading for psychiatric disorder.

\section{Discussion}

Children with ADHD who carry large, rare CNVs were found to be indistinguishable from children without CNVs in terms of the pattern and severity of ADHD symptoms and psychiatric comorbidity. Nor were there any pre-/perinatal, developmental or familial markers of large, rare CNVs. This suggests that large, rare CNVs do not appear to be associated with an atypical form of disorder.

The IQ scores for this sample were normally distributed and, in keeping with previous studies of $\mathrm{ADHD},{ }^{30,31}$ the IQ distribution was comparable to the normal population but with a lower mean. Carriers of large, rare CNVs had a significantly higher rate of intellectual disability (as previously reported in a subsample of the present study) and there were associations with lower IQ scores and reading ability, although the latter did not survive correction for multiple testing. However, there was no relationship between possession of CNVs and IQ in those without intellectual disability. The higher rate of CNVs in children with ADHD and intellectual disability might be explained by several factors. First, as shared genetic and familial risk factors contribute to the association between ADHD and lower IQ in the general population, ${ }^{31,32} \mathrm{CNV}$ s might have a common risk effect on these two different but related neurodevelopmental problems. Given that we have previously observed an overlap of CNVs found in ADHD with those found in schizophrenia and autism, ${ }^{9}$ the hypothesis that CNVs influence multiple neurodevelopmental phenotype outcomes is plausible. ${ }^{33}$ A second possibility is that $\mathrm{CNV}$ s might be increasing ADHD risk through effects on cognition and learning. ${ }^{33}$ This would explain our observed association between $\mathrm{CNVs}$, intellectual disability and reading problems. However, the lack of association between the presence of CNVs and IQ in children without intellectual disability is inconsistent with this view. Overall, regardless of explanation, the results suggest that large, rare CNVs in $\mathrm{ADHD}$, although more common in individuals with intellectual disability, are not confined to this group and are relevant across the IQ spectrum. Nevertheless, given the high rate of large, rare CNVs in children with intellectual disability, as we have previously highlighted, ${ }^{9}$ this group of children (with both ADHD and intellectual disability) might benefit from a clinical genetics opinion.

As already highlighted, structural variants including large, rare CNVs are increasingly being considered to contribute to the risk of ADHD, autism and schizophrenia. ${ }^{1-9}$ It had been well recognised, prior to the recent $\mathrm{CNV}$ studies, that there are specific 'syndromic' types of ADHD, autism and schizophrenia that appear to be caused by structural chromosomal abnormalities. For example, chromosome 22q11 microdeletion syndrome (velocardiofacial syndrome) is associated with increased risks of ADHD and schizophrenia. ${ }^{34}$ There is some work, however, to

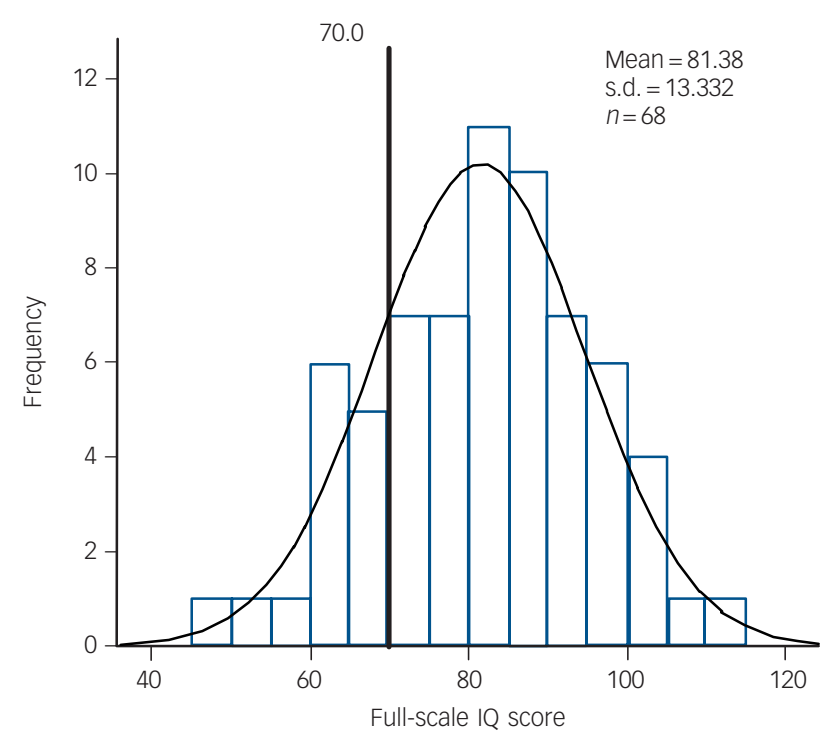

Fig. 2 Distribution of IQ scores of all the children with copy number variants. 


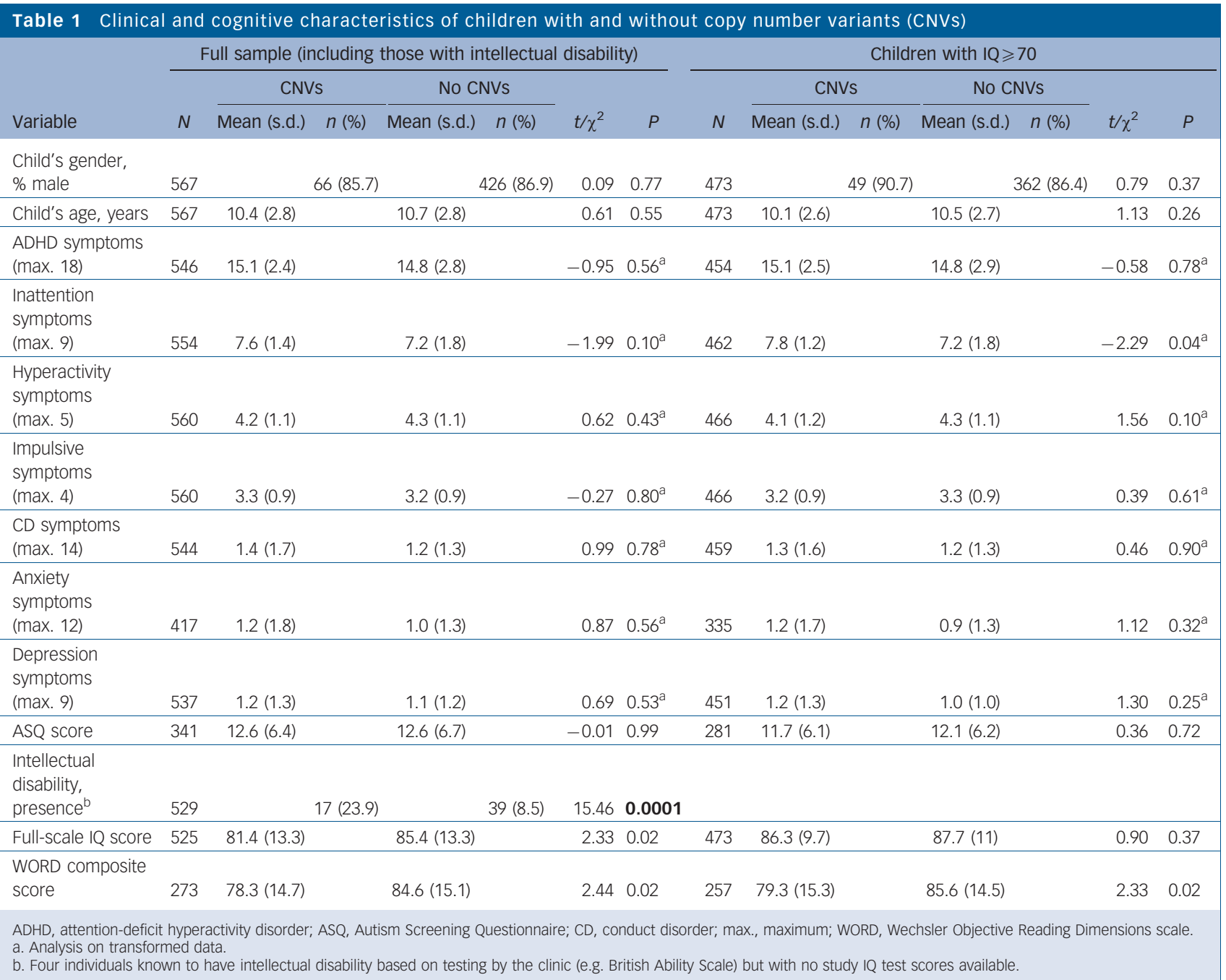

suggest that the pattern of clinical features of ADHD might be different in this group from those with 'idiopathic ADHD'. One study found that children with ADHD and velocardiofacial syndrome, when compared with idiopathic ADHD, showed higher rates of ADHD inattentive type and comorbidity. ${ }^{35}$ In terms of symptom presentation, we found that children with ADHD who possess large, rare CNVs when ascertained from non-specialist clinics were clinically indistinguishable from those who do not show such mutations. However, the mean level of inattention symptoms was higher in the CNV carriers and it is possible that our sample size was not large enough to detect a significant difference. They also did not differ in terms of familial loading for ADHD and other psychiatric disorders. These results are in keeping with the view that these individuals do not have atypical, rare, syndromic forms of ADHD.

There are only a few studies investigating the phenotypic manifestations of CNVs in other disorders. One study was based on 100 individuals with autism-spectrum disorder. ${ }^{36}$ The sample was ascertained for developmental complexity and CNVs were rated as present if considered pathogenic (de novo or absent in controls) but psychiatric phenotype data were not available. Those with pathogenic CNVs were most strongly distinguished by a higher rate of intellectual disability but not by pre-/perinatal factors. Other studies of autism-spectrum disorder have been mixed. ${ }^{37}$ Interestingly, some studies have found associations between specific CNVs and larger and smaller head sizes in intellectual disability and schizophrenia. ${ }^{38}$ We did not have measures of head circumference. Others have also suggested that higher paternal age is associated with autism ${ }^{39}$ and schizophrenia, ${ }^{40}$ but not ADHD, ${ }^{41}$ and it is this that might result in increased rates of mutations in sperm and offspring genomic alterations. ${ }^{42}$ In our study, there was no relationship between those carrying a $\mathrm{CNV}$ and older parental age.

Although our sample is the largest $\mathrm{CNV}$ study of ADHD published to date, there are a number of limitations. First, the sample size may have been too small to distinguish phenotypic differences of small effect size. Second, we did not have data on whether the CNVs in this full sample were de novo or inherited to test these separately. A challenge to examining parent of origin effects in ADHD in UK community clinic samples is that many fathers are not available. We also had no formal assessments of dysmorphic features or detailed assessments of subtle congenital anomalies. Another issue is that in most CNV studies, including our own, large, rare CNVs are located at different chromosomal loci and it is likely that all CNVs are not equally predisposing. Finally, although an increased burden of CNVs has been reported in ADHD and other neurodevelopmental disorders, it is difficult to assess whether they play a causal role. We cannot determine that by observing association alone.

In summary, rare structural variants have increasingly been implicated as contributing to ADHD and other neurodevelopmental disorders. However, it is not known whether the form of ADHD that occurs in carriers of large, rare CNVs is typical of the disorder as a whole. Our results suggest that, apart 


\begin{tabular}{|c|c|c|c|c|c|c|c|c|c|c|c|c|c|c|}
\hline \multirow[b]{3}{*}{ Variable } & \multicolumn{7}{|c|}{ Full sample (including those with intellectual disability) } & \multicolumn{7}{|c|}{ Children with $\mathrm{IQ} \geqslant 70$} \\
\hline & \multirow[b]{2}{*}{$N$} & \multicolumn{2}{|c|}{ CNVs } & \multicolumn{2}{|c|}{ No CNVs } & \multirow[b]{2}{*}{$t / \chi^{2}$} & \multirow[b]{2}{*}{$P$} & \multirow[b]{2}{*}{ N } & \multicolumn{2}{|c|}{ CNVs } & \multicolumn{2}{|c|}{ No CNVs } & \multirow[b]{2}{*}{$t / \chi^{2}$} & \multirow[b]{2}{*}{$P$} \\
\hline & & Mean (s.d.) & $n(\%)$ & Mean (s.d.) & $n(\%)$ & & & & Mean (s.d.) & $n(\%)$ & Mean (s.d.) & $n(\%)$ & & \\
\hline $\begin{array}{l}\text { Maternal age } \\
\text { at birth, years }\end{array}$ & 519 & $25.6(6)$ & & $25.7(6.1)$ & & 0.12 & $0.89^{\mathrm{a}}$ & 440 & $25.3(6)$ & & $25.7(6)$ & & 0.42 & $0.62^{\mathrm{a}}$ \\
\hline $\begin{array}{l}\text { Paternal age } \\
\text { at birth, years }\end{array}$ & 496 & $29(7.1)$ & & $28.9(7.9)$ & & -0.05 & $0.86^{\mathrm{a}}$ & 424 & $29.1(7.2)$ & & $28.8(7.7)$ & & -0.19 & $0.81^{\mathrm{a}}$ \\
\hline $\begin{array}{l}\text { Maternal smoking } \\
\text { during pregnancy, } \\
\text { presence }\end{array}$ & 539 & & $40(57.1)$ & & $214(45.6)$ & 3.24 & 0.07 & 456 & & $28(53.8)$ & & 177 (43.8) & 1.88 & 0.17 \\
\hline $\begin{array}{l}\text { Paternal smoking } \\
\text { during pregnancy, } \\
\text { presence }\end{array}$ & 357 & & $23(48.9)$ & & $175(56.5)$ & 0.93 & 0.33 & 288 & & $17(53.1)$ & & 137 (53.5) & 0.00 & 0.97 \\
\hline Birth weight, g & 530 & 3354 (623) & & 3254 (638) & & -1.20 & 0.23 & 451 & 3393 (558) & & 3270 (639) & & -1.30 & 0.20 \\
\hline $\begin{array}{l}\text { Child spent time } \\
\text { in SCBU, presence }\end{array}$ & 497 & & $6(9.4)$ & & $59(13.6)$ & 0.89 & 0.35 & 421 & & $4(8.3)$ & & $51(13.7)$ & 1.07 & 0.30 \\
\hline $\begin{array}{l}\text { Serious medical } \\
\text { condition, } \\
\text { presence }\end{array}$ & 426 & & $0(0)$ & & $15(4)$ & 2.21 & 0.14 & 355 & & $0(0)$ & & $14(4.4)$ & 1.70 & 0.19 \\
\hline $\begin{array}{l}\text { Language delay, } \\
\text { presence }\end{array}$ & 269 & & $9(25)$ & & $71(30.5)$ & 0.45 & 0.50 & 228 & & $6(21.4)$ & & $55(27.5)$ & 0.46 & 0.50 \\
\hline $\begin{array}{l}\text { Motor delay, } \\
\text { presence }\end{array}$ & 444 & & 35 (61.4) & & $215(55.6)$ & 0.69 & 0.41 & 364 & & $22(55)$ & & $174(53.7)$ & 0.02 & 0.88 \\
\hline $\begin{array}{l}\text { Low family } \\
\text { income, presence }\end{array}$ & 308 & & $28(70)$ & & $161(60.1)$ & 1.45 & 0.23 & 255 & & $18(64.3)$ & & $131(57.7)$ & 0.44 & 0.51 \\
\hline $\begin{array}{l}\text { Low parental } \\
\text { education, } \\
\text { presence }\end{array}$ & 324 & & $10(25)$ & & $80(28.2)$ & 0.18 & 0.68 & 265 & & $4(14.3)$ & & $54(22.8)$ & 1.06 & 0.30 \\
\hline $\begin{array}{l}\text { Family history } \\
\text { of psychiatric } \\
\text { disorder, } \\
\text { presence }\end{array}$ & 384 & & $19(39.6)$ & & $137(40.8)$ & 0.03 & 0.88 & 308 & & $11(35.5)$ & & 108 (39) & 0.14 & 0.70 \\
\hline $\begin{array}{l}\text { Maternal ADHD } \\
\text { symptoms } \\
\text { (max. 18) }\end{array}$ & 398 & $3.3(4.5)$ & & $3.3(4.6)$ & & 0.00 & $0.88^{\mathrm{b}}$ & 337 & $2.7(4)$ & & $3.2(4.4)$ & & 0.62 & $0.53^{b}$ \\
\hline $\begin{array}{l}\text { Paternal ADHD } \\
\text { symptoms } \\
\text { (max. 18) }\end{array}$ & 222 & $4.9(5.2)$ & & $4(4.6)$ & & -0.97 & $0.98^{\mathrm{b}}$ & 187 & $3.2(4)$ & & $3.6(4.1)$ & & 0.46 & $0.33^{b}$ \\
\hline
\end{tabular}

from an increased risk of CNVs in children with comorbid intellectual disability, large, rare CNVs do not appear to be restricted to an atypical subgroup of children with ADHD. These findings have implications for selecting populations for $\mathrm{CNV}$ screening and suggest that other classes of rare mutations might also be found in typical clinical cases.

\footnotetext{
Kate Langley, PhD, Joanna Martin, BSc (Hons), Department of Psychological Medicine and Neurology, and MRC Centre for Neuropsychiatric Genetics, Department of Psychological Medicine and Neurology, Cardiff University; Sharifah Shameem Agha, MSC, Department of Psychological Medicine and Neurology, and MRC Centre for Neuropsychiatric Genetics, Department of Psychological Medicine and Neurology, Cardiff University; and Child and Adolescent Mental Health Services Network, Cwm Taf Healthboard; Charlotte Davies, BSC (Hons), Evangelia Stergiakouli, PhD, Peter Holmans, PhD, Nigel Williams, PhD, Michael Owen, FRCPsych, Michael Peter Holmans, PhD, Nigel Williams, PhD, Michael Owen, FRCPsych, Michae
O'Donovan, FRCPsych, Anita Thapar, FRCPsych, Department of Psychological Medicine and Neurology, and MRC Centre for Neuropsychiatric Genetics, Department of Psychological Medicine and Neurology, Cardiff University, UK

Correspondence: Professor Anita Thapar, MRC Centre for Neuropsychiatric Genetics, Department of Psychological Medicine and Neurology, School of Medicine, Cardiff University, 4th Floor Main Building, Heath Park, Cardiff CF14 4XN, UK. Email: thapar@cardiff.ac.uk

First received 20 Jan 2011, final revision 6 Apr 2011, accepted 16 Jun 2011
}

\section{Funding}

This work has been funded by the Wellcome Trust, Action Research and Baily Thomas Charitable Trust.

\section{Acknowledgements}

We are very grateful to all the families who participated in this project and the clinicians who supported the work. We thank Dr Irina Zaharieva for genotyping the samples, Ms Emma Evans for initial assistance with the data and Dr Ajay Thapar for rating the medical disorders.

\section{References}

1 Abrahams BS, Geschwind DH. Advances in autism genetics: on the threshold of a new neurobiology. Nat Rev Genet 2008; 9: 341-55.

2 Cook Jr EH, Scherer SW. Copy-number variations associated with neuropsychiatric conditions. Nature 2008; 455: 919-23.

3 Glessner JT, Wang K, Cai G, Korvatska O, Kim CE, Wood S, et al. Autism genome-wide copy number variation reveals ubiquitin and neuronal genes. Nature 2009; 459: 569-73. 
4 Owen MJ, Craddock N, O'Donovan MC. Suggestion of roles for both common and rare risk variants in genome-wide studies of schizophrenia. Arch Gen Psychiatry 2010; 67: 667-73.

5 Sebat J, Levy DL, McCarthy SE. Rare structural variants in schizophrenia: one disorder, multiple mutations; one mutation, multiple disorders. Trends Genet 2009; 25: 528-35.

6 Stefansson H, Rujescu D, Cichon S, Pietilainen OP, Ingason A, Steinberg S, et al. Large recurrent microdeletions associated with schizophrenia. Nature 2008; 455: 232-6.

7 Elia J, Gai X, Xie HM, Perin JC, Geiger E, Glessner JT, et al. Rare structural variants found in attention-deficit hyperactivity disorder are preferentially associated with neurodevelopmental genes. Mol Psychiatry 2010; 15 637-46

8 Lesch KP, Selch S, Renner TJ, Jacob C, Nguyen TT, Hahn T, et al. Genomewide copy number variation analysis in attention-deficit/hyperactivity disorder: association with neuropeptide $Y$ gene dosage in an extended pedigree. Mol Psychiatry 2010; 16: 491-503.

9 Williams NM, Zaharieva I, Martin A, Langley K, Mantripragada K, Fossdal R, et al. Rare chromosomal deletions and duplications in attention-deficit hyperactivity disorder: a genome-wide analysis. Lancet 2010; 376: 1401-8.

10 American Psychiatric Association. Diagnostic and Statistical Manual of Mental Disorders (4th edn) (DSM-IV). APA, 1994.

11 American Psychiatric Association. Diagnostic and Statistical Manual of Mental Disorders (3rd edn, revised) (DSM-III-R). APA, 1987.

12 World Health Organization. The ICD-10 Classification of Mental and Behavioural Disorders: Clinical Description and Diagnostic Guidelines. WHO, 1992.

13 Berument SK, Rutter M, Lord C, Pickles A, Bailey A. Autism screening questionnaire: diagnostic validity. Br J Psychiatry 1999; 175: 444-51.

14 Angold A, Prendergast M, Cox A, Harrington R, Simonoff E, Rutter M. The Child and Adolescent Psychiatric Assessment (CAPA). Psychol Med 1995; 25 739-53.

15 Holmes J, Lawson D, Langley K, Fitzpatrick H, Trumper A, Pay H, et al. The Child Attention-Deficit Hyperactivity Disorder Teacher Telephone Interview (CHATTI): reliability and validity. Br J Psychiatry 2004; 184: 74-8.

16 Conners CK. A teacher rating scale for use in drug studies with children. Am J Psychiatry 1969; 126: 884-8.

17 Angold A, Costello EJ. A test-retest reliability study of child-reported psychiatric symptoms and diagnoses using the Child and Adolescent Psychiatric Assessment (CAPA-C). Psychol Med 1995; 25: 755-62.

18 Weschler D. Weschler Intelligence Scale for Children. Third Edition. Psychological Corporation, 1992.

19 Weschler D. Weschler Intelligence Scale for Children - Fourth Edition (WISC-IV). Administration and Scoring Manual. Psychological Association, 2003.

20 Wechsler D. Wechsler Objective Reading Dimensions. Psychological Corporation, 1993.

21 Lewis SW, Murray RM. Obstetric complications, neurodevelopmental deviance, and risk of schizophrenia. J Psychiatr Res 1987; 21: 413-21.

22 Rice F, Lewis A, Harold G, van den Bree M, Boivin J, Hay DF, et al. Agreement between maternal report and antenatal records for a range of pre and peri-natal factors: the influence of maternal and child characteristics. Early Hum Dev 2007; 83: 497-504.

23 Fowler T, Langley K, Rice F, Whittinger N, Ross K, van Goozen S, et al. Psychopathy traits in adolescents with attention-deficit hyperactivity disorder. Br J Psychiatry 2009; 194: 62-7.

24 Langley K, Holmans PA, van den Bree MB, Thapar A. Effects of low birth weight, maternal smoking in pregnancy and social class on the phenotypic manifestation of attention deficit hyperactivity disorder and associated antisocial behaviour: investigation in a clinical sample. BMC Psychiatry 2007; 7: 26

25 Thapar A, Harrington R, Ross K, McGuffin P. Does the definition of ADHD affect heritability? J Am Acad Child Adolesc Psychiatry 2000; 39: 1528-36.

26 Barkley RA, Murphy KR. Attention-Deficit Hyperactivity Disorder: A Handbook for Diagnosis and Treatment (2nd edn). Guilford Press, 1998.

27 Kessler RC, Adler L, Barkley R, Biederman J, Conners CK, Demler O, et al. The prevalence and correlates of adult ADHD in the United States: results from the National Comorbidity Survey Replication. Am J Psychiatry 2006; 163: 716-23.

28 Wang K, Li M, Hadley D, Liu R, Glessner J, Grant SF, et al. PennCNV: an integrated hidden Markov model designed for high-resolution copy number variation detection in whole-genome SNP genotyping data. Genome Res 2007; 17: 1665-74.

29 Simonoff E, Pickles A, Wood N, Gringras P, Chadwick O. ADHD symptoms in children with mild intellectual disability. J Am Acad Child Adolesc Psychiatry 2007; 46: 591-600.

30 Biederman J, Faraone SV, Mick E, Williamson S, Wilens TE, Spencer TJ, et al. Clinical correlates of ADHD in females: findings from a large group of girls ascertained from pediatric and psychiatric referral sources. J Am Acad Child Adolesc Psychiatry 1999; 38: 966-75.

31 Kuntsi J, Eley TC, Taylor A, Hughes C, Asherson P, Caspi A, et al. Co-occurrence of ADHD and low IQ has genetic origins. Am J Med Genet B Neuropsychiatr Genet 2004; 124B: 41-7.

32 Wood AC, Rijsdijk F, Johnson KA, Andreou P, Albrecht B, Arias-Vasquez A, et al. The relationship between ADHD and key cognitive phenotypes is not mediated by shared familial effects with IQ. Psychol Med 2011; 41: 861-71.

33 O'Donovan MC, Kirov G, Owen MJ. Phenotypic variations on the theme of CNVs. Nat Genet 2008; 40: 1392-3.

34 Vorstman JA, Morcus ME, Duijff SN, Klaassen PW, Heineman-de Boer JA Beemer FA, et al. The 22q11.2 deletion in children: high rate of autistic disorders and early onset of psychotic symptoms. J Am Acad Child Adolesc Psychiatry 2006; 45: 1104-13.

35 Antshel KM, Faraone SV, Fremont W, Monuteaux MC, Kates WR, Doyle A, et al. Comparing ADHD in velocardiofacial syndrome to idiopathic ADHD: a preliminary study. J Atten Disord 2007; 11: 64-73.

36 Qiao $Y$, Riendeau N, Koochek M, Liu X, Harvard C, Hildebrand MJ, et al. Phenomic determinants of genomic variation in autism spectrum disorders. J Med Genet 2009; 46: 680-8.

37 Lintas C, Persico AM. Autistic phenotypes and genetic testing: state-of-theart for the clinical geneticist. J Med Genet 2009; 46: 1-8.

38 McCarthy SE, Makarov V, Kirov G, Addington AM, McClellan J, Yoon S, et al. Microduplications of 16p11.2 are associated with schizophrenia. Nat Genet 2009; 41: 1223-7.

39 Reichenberg A, Gross R, Weiser M, Bresnahan M, Silverman J, Harlap S, et al. Advancing paternal age and autism. Arch Gen Psychiatry 2006; 63: 1026-32.

40 Malaspina D, Harlap S, Fennig S, Heiman D, Nahon D, Feldman D, et al. Advancing paternal age and the risk of schizophrenia. Arch Gen Psychiatry 2001; 58: 361-7.

41 Gabis L, Raz R, Kesner-Baruch Y. Paternal age in autism spectrum disorders and ADHD. Pediatr Neurol 2010; 43: 300-2.

42 Hultman $\mathrm{CM}$, Sandin S, Levine SZ, Lichtenstein P, Reichenberg A. Advancing paternal age and risk of autism: new evidence from a population-based study and a meta-analysis of epidemiological studies. Mol Psychiatry 2010; Nov 30. Epub ahead of print. 